\title{
Retinal Infarction as a Rare Complication of Cerebral Angiography in a Patient with Acute Cerebral Infarction Caused by Moyamoya Disease
}

\author{
Xiaodong Chen*1,2, Ying Wang ${ }^{1}$, Yuanwei Wang ${ }^{1}$ and Gelin $\mathrm{Xu}^{2}$ \\ ${ }^{1}$ Department of Neurology, Shuyang People's Hospital, China \\ ${ }^{2}$ Department of Neurology, Jinling Hospital, China
}

Received: 眥: November 02, 2018; Published: 制: November 09, 2018

*Corresponding author: Xiaodong Chen, Department of Neurology, Shuyang Hospital Affiliated to Xuzhou Medical University, Shuyang, Jiangsu Province 223600, China

Abbreviations: MRI: Magnetic Resonance Imaging; MMD: Moyamoya Disease; DSA: Digital Subtraction Angiogram

\section{Case Report}

A 41-year-old Chinese woman with unremarkable medical history, not taking any medication, presented initially with a sudden onset of slurred speech that lasted 9 hours. On examination, Her tongue was deviated to the right on protrusion, but no other neurologic abnormality was elicited. Results from laboratory tests including complete blood count, liver and renal functions, thyroid function, blood glucose, cholesterol, homocysteine, Coagulation profile; erythrocyte sedimentation rate, C-reactive protein; assays for antinuclear antibodies, anti-DNA, antiphospholipid antibodies, complements and rheumatoid factor were all normal or negative. Serologic tests for Treponema pallidum, Toxoplasma gondii, Borrelia burgdorferi and human immunodeficiency virus revealed no abnormality. Neither Transesophageal echocardiography nor prolonged electrocardiography revealed any cardiogenic emboli.

On admission, diffusion weighted magnetic resonance imaging (MRI) revealed an acute infarct in the left frontal lobe; Fluid attenuated inversion recovery MRI showed multiple small chronic infarcts in the bilateral deep white matter, basal ganglia(not shown); MRA showed bilateral stenosis or occlusion of the terminal ICA and/or middle cerebral artery with abnormal vascular networks in the basal ganglia, which suggested a diagnosis of Moyamoya disease (MMD) (Figure 1) (Panel A).The patient was started on antiplatelet drugs ( a combination of aspirin and clopidogrel) and atorvastatin. The digital subtraction angiogram(DSA) study of the aortic arch and cervical-cerebrovascular on admission day 2 confirmed the diagnosis of MMD( Panel B 1-5) (Figure 1). However, the patient also complained about impaired ("foggy") vision of the right eye. Bedside examination demonstrated a right eye inferior lateral visual field defect. Dilated fundus examination disclosed that the left eye was normal but that the right eye contained an area of retinal opacification seen as ischemic whitening beginning some distance from the disc (Panel C-1 ) (Figure 1). Intravenous fluorescein angiography was performed the same time revealed no persisting vessel occlusion in both eyes (Panel C-2 ) (Figure 1), most likely due to transient thromboembolism as a rare and uncommon complication of DSA.

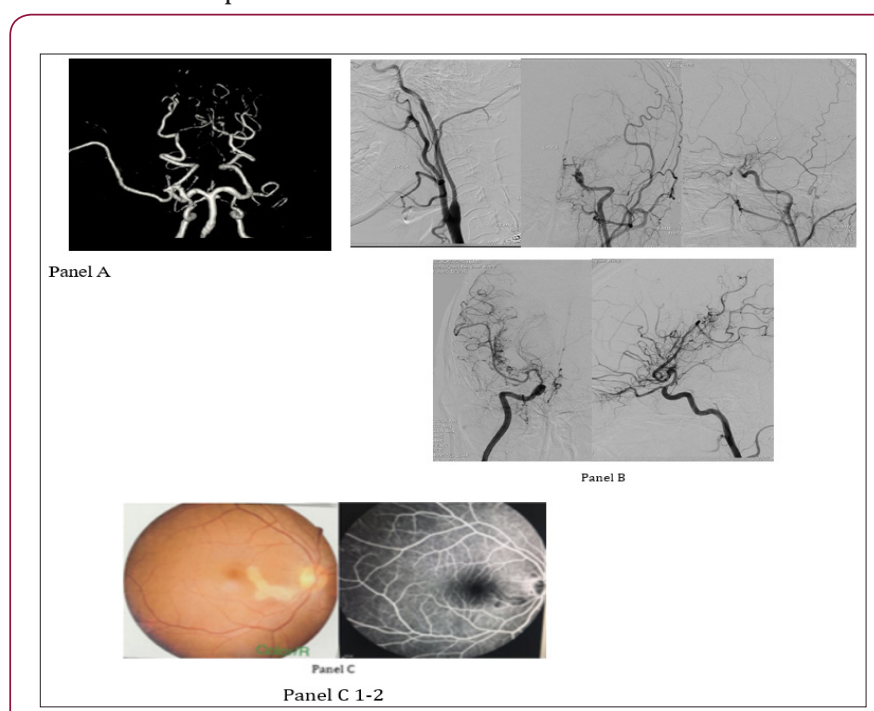

Figure 1: Diagnosis of Moyamoya Disease.

Her Slurred speech improved one week after admission. At the 3-month follow-up, minimal improvement in impaired vision 
and there was no further stroke during 90 days after the index stroke. The incidence of ophthalmic complications in diagnostic angiography is extremely low, and differential diagnosis should always include contrast induced transient cortical blindness, retinal artery occlusion, amaurosis fugax and hysterical blindness [1]. Recently, Bolognese $\mathrm{M}$ et al reported a case of retinal ischemia in a patient who had undergone an mechanical thrombectomy [2]. we present an intriguing case of a 41-year-old woman with retinal infarction soon after diagnostic cerebral angiography and emphasize this rare post catheterization complication for future neuroradiologists and ophthalmologists.

\section{ISSN: 2574-1241}

DOI: $10.26717 / B J S T R .2018 .10 .002020$

Xiaodong Chen. Biomed J Sci \& Tech Res

This work is licensed under Creative Commons Attribution 4.0 License

Submission Link: https://biomedres.us/submit-manuscript.php

\section{Funding}

This research received no specific grant from any funding agency in the public, commercial, or not-for-profit sectors.

\section{References}

1. Willinsky RA, Taylor SM, Ter Brugge K, Farb RI, Tomlinson G, et al. (2003) Neurologic complications of cerebral angiography: prospective analysis of 2,899 procedures and review of the literature. Radiology 227(2): 522528.

2. Bolognese M, von Hessling A, Jordi F (2018) Teaching Neuro Images: Visual loss as a rare complication of mechanical thrombectomy. Neurology 90(4): e355-e356.

$\begin{array}{ll}\text { BIOMEDICAL } & \text { Assets of Publishing with us } \\ \text { RESEARCHES } & \text { - Global archiving of articles } \\ \text { - Immediate, unrestricted online access }\end{array}$

